\title{
Information der SAGOM
}

Manuelle Medizin 2017 · 55:417

https://doi.org/10.1007/s00337-017-

0344-7

C Springer Medizin Verlag $\mathrm{GmbH}$, ein

Teil von Springer Nature 2017

V.i.S.d.P.:

Dr. B. Weber

Bahnhofstrasse 63

$\mathrm{CH}-8887$ Mels

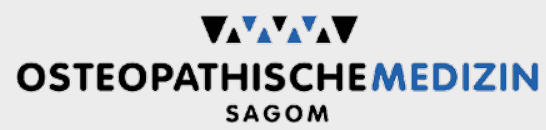

OSTEOPATHISCHEMEDIZIN

SAGOM

\section{Schweizerische Ärztegesellschaft} für Osteopathische Medizin SAGOM

\section{Masterkurse der SAGOM 2017}

(In Kooperation mit DGOM)

Die Kurse finden alle in Freiburg (D) statt

01.12.-03.12. Mechanical link 6

(Nach Paul Chauffour D. O.)

Kursleiter: Eric Prat, D. O. F/D

Kenntnisvoraussetzung: LMO 1

\section{Einführung in die Osteopathie für Manual-Mediziner} und Manual-Therapeuten in Zusammenarbeit von

\section{SAMM und SAGOM}
14. - 16. Januar 2018 Muskelenergie Techniken (MET plus)
Murten
24. - 26. Juni $2018 \quad$ Myofasciale Techniken (Mf3 plus)
Murten
1. - 3. November 2018 Fazilitated Positional Release (FPR)
Diessenhofen

\section{Anmeldungen:}

DGOM Sekretariat

c/o Akademie für Gesundheitsfachberufe

am Diakonie Krankenhaus Belchenstraße 1 - 5, 68163 Mannheim

Telefonnummer des Sekretariats: 0621/436266 92

Faxnummer: 0621/436266 91

Email: kontakt@dgom.info

Ansprechpartnerin in allen Fragen zu DGOM Kursen ist Frau Citius.

Anmeldungen für die Kurse in Kooperation SAMM/SAGOM können über die Website der SAMM vorgenommen werden:

http://www.samm.ch/de/fortbildung/angebotsuebersicht-samm.

html

\section{SAGOM Vereinssekretariat:}

SAGOM Sekretariat

c/o Praxis Dr. med. Bruno Weber Bahnhofstrasse 63

$\mathrm{CH} 8887$ Mels

Tel +41817200540

Fax +41817200545

E Mail: info@sagom.ch www.sagom.ch

Bitte beachten Sie auch das Curriculum der DGOM. 